F. med. Genet. (1966). 3, 169.

\title{
Gene Effect in Carriers of Anhidrotic Ectodermal Dysplasia*
}

\author{
C. B. KERR†, R. S. WELLS, and K. E. COOPER
}

From the Medical Research Council Population Genetics Research Unit, Headington, Oxford, and the Department of the Regius Professor of Medicine, Radcliffe Infirmary, Oxford

\section{Anhidrotic Ectodermal Dysplasia}

In an extensive review of different forms of hereditary ectodermal dysplasia, Cockayne (I933) recognized two types of inheritance for the variety characterized by anhidrosis, hypotrichosis, and complete or partial anodontia. He postulated an $\mathrm{X}$-linked recessive gene in families where males alone were affected and an autosomal dominant gene where females were involved. However, as pointed out by Levit (1936), females never exhibited the full syndrome, and the inheritance in all families reviewed by Cockayne was consistent with $\mathrm{X}$-linkage.

Many subsequent reports of males with X-linked anhidrotic ectodermal dysplasia have established a remarkably consistent phenotype. The outstanding feature is lack of sweating, as perceived by the patient and on external examination of the skin. This results from a gross but not absolute deficiency of sweat glands. Hair on the scalp and eyebrows is sparse and fine and usually lacking on the body surfaces though adults may develop a beard. Noneruption of teeth at either dentition may result in complete anodontia but more frequently a few malformed teeth are present. Lack of teeth provides one aspect of the characteristic facies which together with hypotrichosis, prominent bossing of the forehead, and typically depressed bridge of the nose renders affected males similar in appearance.

The evidence for an autosomal dominant variety of anhidrotic ectodermal dysplasia remains inconclusive. Some confusion with the hidrotic variety is evident in certain reports. This latter form is characterized by hypotrichosis and dystrophy of the nails in association with normal sweating and

Received December 6, 1965.

* Requests for reprints to M.R.C. Population Genetics Research Unit, Old Road, Headington, Oxford.

† Present address: School of Public Health and Tropical Medicine, University of Sydney, Sydney, New South Wales, Australia. dentition. It was clearly distinguished from the anhidrotic variety in 1929 by Weech, and numerous studies have confirmed autosomal dominant inheritance (Clouston, 1939; Bruno and Engelhardt, I944; White, 1964; Mallmann-Mühlberger and Helwig, 1964). In other reports alleged instances of autosomal dominant anhidrotic ectodermal dysplasia were either recorded without adequate details or were very atypical. The father-son transmission in Battersby's (1936) pedigree was based on hearsay evidence and remote from the investigated part of the family where inheritance was consistent with $\mathrm{X}$-linkage. Another widely-quoted example of autosomal inheritance concerns the family reported by Brain (1937), but mention of 'nail dystrophy' in the father of a male with the anhidrotic form cannot be accepted as evidence of gene effect. The same reasoning applies to the family described by Lipton and Roberts (1950), where the claim for autosomal inheritance was based on a history of one abnormal deciduous tooth in the father. Several unique families have been described where the pattern of inheritance suggested autosomal dominant anhidrotic ectcdermal dysplasia associated with mental retardation (Halperin and Curtis, 1942), neurolabyrinthitis (Helweg-Larsen and Ludvigsen, 1946), or primary hypogonadism (Mohler, 1959). Females with the full syndrome and no affected male relatives have been reported either as sporadic cases (Wagner, I952), offspring of an uncle-niece mating (Lipscomb and Manonmani, 1952), or in three generations of one family (Bernard, Giraud, Rouby, and Hartung, 1963). Clearly, the condition is genetically heterogeneous, but the evidence for an X-linked form fully expressed in males is indisputable.

Phenotype in Males with X-linked Anhidrotic Ectodermal Dysplasia. The phenotype in males results from an incomplete development of the epidermis and its appendages. A quantitative 
deficiency in hair follicles due to hypoplasia or absence of pilosebaceous structures is responsible for hypotrichosis. The dental defects are presumably caused by failure of the dental lamina, an epithelial plate derived from ectoderm in the 7 th week of intrauterine life. Complete anodontia has been recorded (Thadani, 1934; Battersby, 1936; Thoma and Allen, 1940), but usually a few misshapen teeth are formed, typically as conical structures in incisor or canine areas.

The deficiency in epidermal sweat glands is generally regarded as complete. However, under experimental conditions of raised environmental temperature, and using a starch-iodine indicator method (Minor 1927), slight sweating has been noted in the axilla (Felsher, 1944; Sackett, Marans, and Hursey, 1956) and on the forehead (Everett, Jump, Sutherland, Savara, and Suher, 1952) or chest (Felsher, 1944). By contrast complete absence of sweating has been reported under identical conditions (Sunderman, 194I ; Lipton and Roberts, 1950; Metson and Williams, 1952). Many skin biopsies have been examined for sweat glands generally with negative results. Most biopsies were taken from the axilla, but negative findings have also been recorded in serial sections of skin from the forehead (Spira, 1947), palmar surfaces (Everett et al., 1952), sole of foot (Upshaw and Montgomery, 1949), pubis (Clouston, I939), abdomen (Zeligs, 1932), and forearm (Grant and Falls, 1944). Sweat glands were demonstrated in deeper layers of the cutis by Sackett et al. (1956), whose patient also sweated under experimental conditions. Dental features and deficiency of hair were far less marked than usual in this patient, which raises the question of a milder X-linked variety. Thannhauser (1936) described a similarly mild case. Sweat glands in forearm skin of a typical case were reported by Rademaker (1933), but some doubt must be cast on this finding because pilocarpine failed to produce sweating which, as noted by others (Lord and Wolfe, 1938), is convincing evidence for the absence of sweat glands.

Lacrimation is generally normal but has been recorded as absent (Thurnam, 1848; Sunderman, 194I) or diminished (Grant and Falls, 1944). Scarcity of mucous glands in the nasopharynx (Upshaw and Montgomery, 1949; Malagon and Taveras, 1956) leads to atrophic rhinitis, and the deficiency or absence of buccal glands in oral mucosa (Sackett et al., 1956) may result in a troublesome lack of secretions. There is no deficiency of sebaceous glands (which may undergo papular degeneration (De Silva, 1939)) or of apocrine glands (Upshaw and Montgomery, 1949).
Mammary tissue may be defective (Clarke and McCance, 1934; Clouston, 1939), presumably a manifestation of the primary ectodermal disordeo and absent nipples were noted in an early repoef (Tendlau, 1902). Tritsch (1963) has confirmed $\frac{\bar{Q}}{\bar{Q}}$ normal karyotype in affected males.

Phenotype in Female Relatives. Female relatives of males with anhidrotic ectodermat dysplasia who were either carriers or has a $50 \%$ probability of heterozygosity have bee reported to show various manifestations of the gene Partial anodontia was most commonly demonis strated (Battersby, 1936; De Silva, 1939; Lipton and Roberts, 1950), and hypotrichosis is frequentl屃 mentioned in older reports, though objective evidence is lacking (De Silva, 1939). Intolerance to heat was occasionally noted by some females (Stadler and Blackstone, 1942; Seagle, 1954), ang Roberts (1929) wrote that three carriers from a larg $\widehat{\oplus}$ family 'were reported to have occasional patches of the body which was smooth and in which the sweas glands did not function'.

Thadani (1934) mentioned hairless non-sweating female relatives of males in the Hindu family first recorded by Darwin (1875) following a communicae tion by W. Wedderburn who noted that '. . . the daughters are never affected though they transmi $\bar{\Phi}$ the tendency to their sons'. Thadani's report wa最 entirely anecdotal and without further detail\& cannot be accepted as evidence of an anhidrotig state in heterozygous females. The same criticism applies to Guilford's (1883) report of a maternaI grandmother who 'never had hair or teeth', and to a brief paper by Glass and Yost (1939) whos mentioned two probably heterozygous females whơ 'had never perspired and lacked mammary glands'

Females with apparently congenital anhidrosis. and ectodermal defects who were sporadic case $\mathcal{Q}$ (Wagner, 1952) or had other similarly affected female relatives (Lipscomb and Manonmani, I952은 Kline, Sidbury, and Richter, 1959; Bernard et al.\$ 1963) have been described. However, as mentionech. above, it is probable that such females are recipi ents of other mutations.

\section{Present Investigation}

If the assumptions of the inactive $\mathrm{X}$ chromosome theory (Lyon, 196I) apply to the present locus then a mosaic distribution of ectodermal defects would be predicted in heterozygous females. AT search for phenotype mosaicism was undertaken? by a detailed study of two genetically provens 
heterozygous females, and more general examination of several other proven or probable carriers.

\section{Case Material and Methods}

Most investigations were undertaken on members of Family A (Fig. I). The family was ascertained through an affected boy III.I, aged 4; his younger brother, III.3, was readily diagnosed at the age of 8 months by the eruption of typically pointed teeth, one in each upper canine area. A male cousin III.5, aged 4, was also affected. The heterozygous mothers II.2, aged 25, and II.4, aged 23, both daughters of the affected male I. I, were studied extensively. Their daughters III.2, aged 3, and III.4, aged 4, each with a half-chance of heterozygosity, were examined clinically.

I

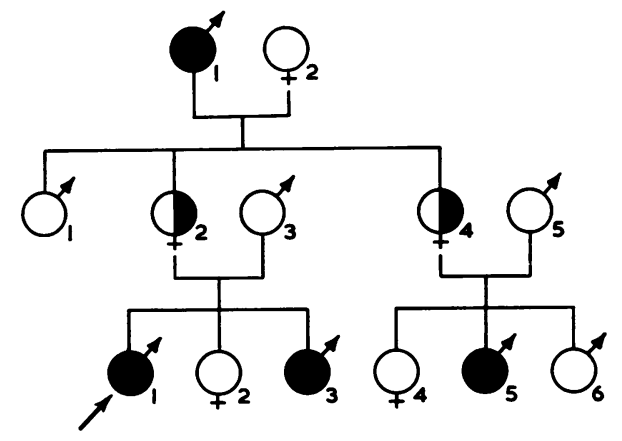

FIG. I. Pedigree of Family A.

Two other heterozygotes were examined. One, aged 3 I (from Family B), was the daughter of an affected man and had a son with anhidrotic ectodermal dysplasia. The other woman, aged 26 (from Family C), had two sons with typical features of the trait, but the elder was additionally affected with ichthyosis hystrix.

The women who volunteered to act as controls for sweat investigations were in good health and aged 24 and 25 years.

Skin biopsies were obtained from the outer surface of the forearm. Sections were stained with haematoxylin and eosin, and with Verhoeff's and van Gieson's stain (the latter to demonstrate elastic fibres and collagen).

Studies on the distribution of sweating in heterozygous females and normal controls were undertaken by a method which was basically that of Minor (1927), as described by Kuno (1956) but using quinazarin compound (quinazarin 2:6 disulphonic acid $28 \%$ (Guttmann, 1940) ) instead of iodine as an indicator of skin moisture. A colourless powder of the following composition: Quinazarin (Burroughs Wellcome), $35 \mathrm{~g}$.; $\mathrm{Na}_{2} \mathrm{CO}_{3}, 30 \mathrm{~g}$.; starch, $60 \mathrm{~g}$., was applied evenly with a fine brush over the face and entire body surface. The subject was then seated in an insulated and heated room with the feet and distal third of legs in hot water until a rectal temperature of $38-38 \cdot 5^{\circ} \mathrm{C}$. was reached. Colour changes on contact with sweat were recorded photographically on black-and-white and colour film.

\section{Results}

(i) Hair. No deficiency in scalp or body hair was found. In particular, a careful examination of forearm and lower limb lanugo hair on heterozygous females A II.2 and II.4 failed to reveal patches of hairless skin, though the possibility of a relative deficiency could not be excluded in the case of II.2.

(ii) Teeth. Examination of teeth was often unsatisfactory because it was not possible to gain a complete history of tooth extractions or to obtain radiographs of the jaws, and a diagnosis of partial anodontia is not reliable without information from these sources. Nevertheless, the following conclusions could be drawn.

(a) Evidence suggestive of abnormal dentition. In family $A$ the heterozygous female II.2 recalled an abnormally sharp and pointed deciduous tooth in the upper canine area. At the second dentition each upper lateral incisor failed to erupt, and the widely spaced central incisors were removed at 9 years of age. Other teeth were subsequently extracted because of dental caries, but there was no evidence of absence or malformation of mandibular teeth. Her daughter appeared to have a normal deciduous dentition. The other heterozygous female II. 4 could not recall her deciduous teeth, but there was absence of at least three permanent teeth: left upper canine, lower lateral incisor, and a lower first premolar. Her daughter had a total of I6 deciduous teeth. Those missing were both upper central incisors and a left incisor and right molar in the lower jaw.

The mother of two affected boys in family C had absence of both upper lateral incisors and a probable absence of a lower premolar, though the latter may have been extracted along with several other lower jaw teeth.

(b) Evidence of normal dentition. There was no indication of anodontia or abnormally formed teeth in the permanent dentition of the heterozygous female from family $B$.

(iii) Sweat glands.

(a) Perception of sweating. With one exception all adult females considered that they sweated in a normal manner and had not observed any regional lack of sweating, either during febrile illnesses, undergoing physical exertion, or in a hot environment. The exception, A II.2, had noticed that her forearms remained dry when other areas were moist with sweat. 


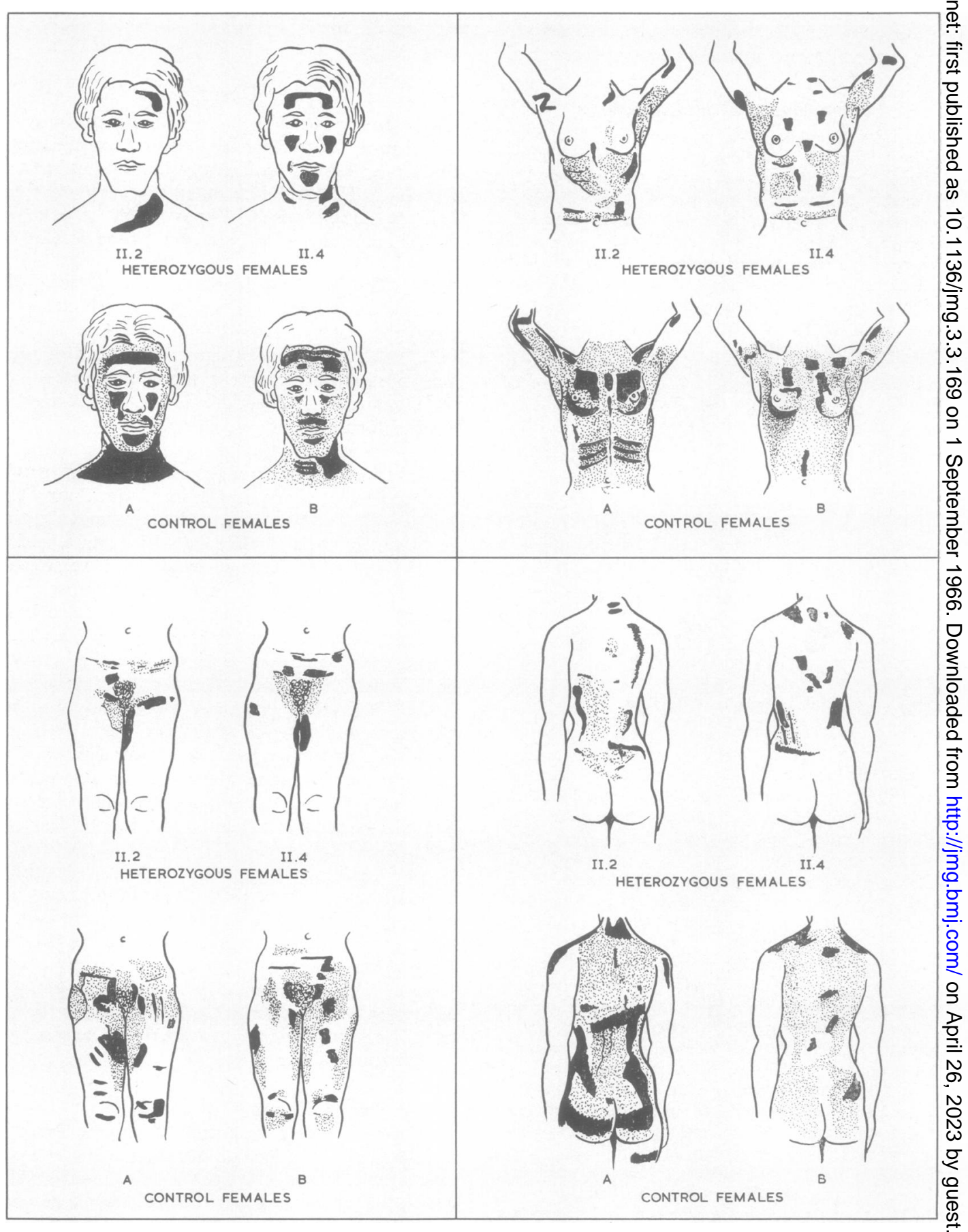

FIG. 2. Regional distribution of sweating induced by heat. Drawings made from black and white prints and colour transparencies. Dark areas represent purple change of quinazarin compound in situ. Stippling represents areas from which dye has been washed by sweat. 


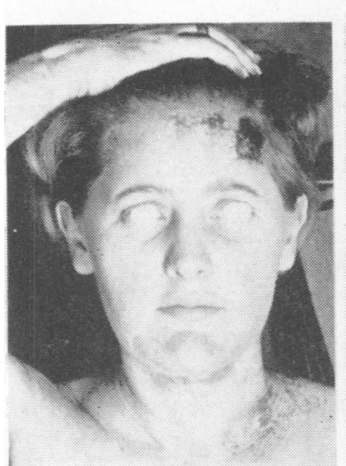

II. 2

HETEROZYGOUS FEMALES

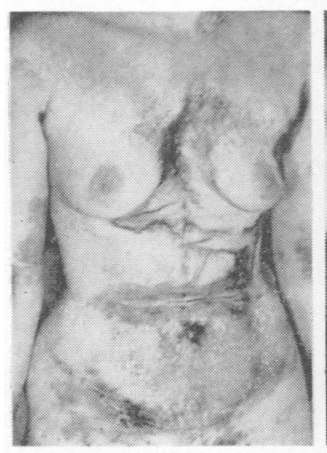

II. 2

HETEROZYGOUS FEMALES

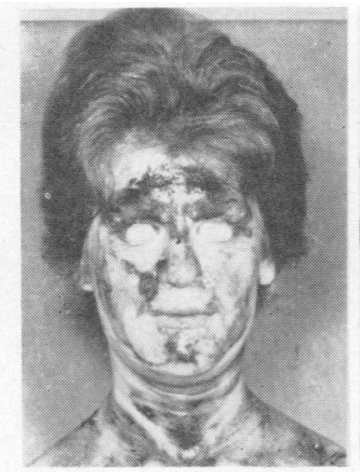

A

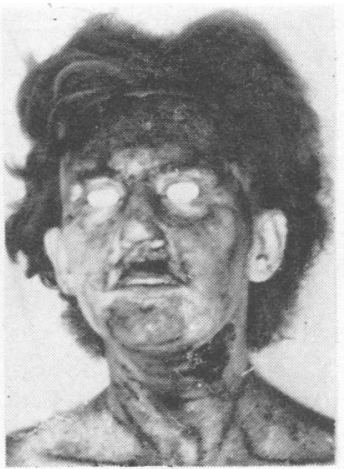

B

CONTROL FEMALES

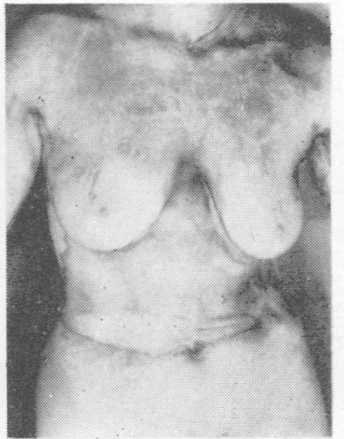

II. 4

FIG. 3. Examples of photographically recorded colour changes in quinazarin compound.

(b) Distribution of sweating on the body surface. Colour changes in quinazarin compound on the body surfaces of two heterozygous females II.2 and II.4 from family $A$ and two normal females were recorded photographically when the rectal temperature reached $38-38 \cdot 5^{\circ} \mathrm{C}$. For comparative purposes, drawings were made from black-and-white prints and colour transparencies to illustrate distribution of dye on various areas of the body surface (Fig. 2). Examples of black-and-white photographs of representative areas are shown in Fig. 3. The latter prints provide a faithful record of areas where dark purple changes represented the effects of sweating in situ. However, areas where dye had been washed away by sweat could not be distinguished clearly. Hence the use of colour transparencies in the construction of drawings because residual light-red coloration or glistening and obviously moist skin could be recognized. These latter changes are represented by stippling on the drawings.
As illustrated in Fig. 2, there was a difference in the extent of sweating for each class of female. The relatively localized distribution in heterozygous females was best demonstrated on the face, chest, and back. By contrast, much of the dye on these areas in both controls had been washed away by sweat. Sweating localized to the left side of the forehead and neck, and more pronounced in the left axilla, was found in heterozygote II.2. The order in which different regions began to sweat was similar for each class of female, though the onset of colour changes occurred after a longer period in heterozygotes. Emotional sweating, indicated by staining in the axillae and on the palms before thermal stimulation in both controls was not seen in either heterozygous female.

(c) Examination of skin sections for sweat glands. In order to establish the histological features in an affected male from family $A$, sections were prepared from a biopsy specimen obtained from the outer surface of the forearm of I.I aged 60. The 
epidermis appeared thinner than normal and the Malpighian layer was rudimentary. In all, 38 serial sections were examined for epidermal appendages. There was no evidence of glandular structures, sweat or sebaceous ducts, hair follicles, and smooth muscle. No abnormality of collagen and elastic fibres was detected in sections stained with Verhoeff and van Gieson.

Examinations were made on 48 serial sections of skin from the forearm of each heterozygous female in family $A$. The epidermis appeared entirely normal in each case. No glandular elements, hair structures, or smooth muscle were detected in sections from II.2. By contrast, 3 sweat glands and 3 sebaceous glands were found in the dermis of II.4, together with muscle fibres of an arrector pilae. Collagen and elastic fibres were normal in each female.

(iv) Other Ectodermal Structures. No defect in nipples, or breast tissue (the latter primarily of mesodermal origin) was observed in any female.

\section{Discussion}

Present data were not sufficient to draw conclusions on the range of phenotypic variability in heterozygous females. However, observations on teeth suggested variation from normal dentition to degrees of partial anodontia and malformed teeth, which is in accordance with previous reports. Partial anodontia has been detected in random members of different normal populations with a frequency varying from $2 \%$ (Werther and Rothenberg, 1939) to about 6\% (Grahnen, 1962). These surveys indicated that teeth were more frequently missing in the permanent dentition, and so the incomplete deciduous set of the female child $A$, III.4 (with a 50\% genetical probability of heterozygosity) can be taken as evidence of the carrier state. The abnormally conical and pointed teeth found in affected males and occasionally in heterozygous females are typical but not pathognomonic (Thoma and Allen, 1940) of the gene for anhidrotic ectodermal dysplasia.

No obvious deficiency in the amount of scalp or body hair was noted among females, nor were there any apparent differences in hair distribution on each side of the body in the heterozygous adults from family $A$.

The density of sweat glands varies considerably over the body surface of normal people. According to Kuno (I956) there are between 120 and 200 active sweat glands per square centimetre of skin on the external surface of the forearm. Skin in this area obtained from an affected male and the heterozygous female A, II.2, did not contain swe glands, whereas 3 sweat glands and other epiderma appendages were found in the heterozygous femate II.4. Sections obtained from the outer surface of the upper arm from 7 persons with normal ski (control material described elsewhere by Wells ang Kerr, I966) were used for comparison, because Kuno (1956) demonstrated a similar density 0 क sweat glands in both areas. Sweat glands were detected in 4 out of 7 normal skin sections (widt $5 \mu)$. No glandular structures were seen in 4. sections (total width $0.2 \mathrm{~mm}$.) of skin from the heterozygote II.2. An estimate of the probabilitso of encountering a sweat gland in a given area of skin is not justified because Kuno's work hag emphasized the irregular distribution of glands Nevertheless, findings in heterozygote II.2 are highly suggestive of a relative deficiency in an areos of skin where sweating was not detected subjectivel nor on experimental stimulation by heat.

Areas of thermal sweating were less extensive $i$ heterozygous females, both by comparison wit $\mathbb{Q}$ control females and with data provided by Kun (1956). The latter used a similar technique, largel\$ on male subjects, and demonstrated considerable variation in the regional distribution of sweatinge However, the distinct patchiness and unilaterat sweating noted in the present heterozygotes has not been found in normal people. There was no evidence that more prolonged heat stimulatio would cause further sweating in heterozygotes. $A \overrightarrow{\vec{S}}$ it was, experimental conditions were extended to the point beyond which gross discomfort would be provoked. The apparent delay in onset of sweating. recorded for each heterozygote was probably dependent on the relative deficiency of active sweat glands. As Kuno has pointed out, the method is unsatisfactory for determining time of onser because appearance of staining is influenced bo several environmental factors.

The results from sweat distribution tests of heterozygous females were consistent with $\$$ quantitative defect of sweat glands. This was. supported by histological findings in one carriern which together with the patchy distribution of sweating is suggestive evidence of tissue mosaicism? as predicted on the inactive $\mathrm{X}$ chromosome theoryw Superficially, relatively large areas of sweating an $\mathbb{}$ non-sweating skin indicate a small number o6 precursor cells in existence at time of inactivationळ Confirmation of this assumption requires more precise quantitation of active sweat glands, and i⿰亻 was hoped to obtain such data by using the metho\& of Sutarman and Thomson (1952) for enumerating? 
individual sweat glands by impressions obtained in plastic media. However, estimates would be meaningful only by comparison with a considerable body of control information, and it was not possible to amass sufficient data from normal females.

The observed variation in dentition is also in keeping with the assumptions of the inactive $\mathrm{X}$ chromosome theory, but it is difficult to explain lack of gene effect on hair. Possibly, the gene products controlled at the X-linked locus exert a more generalized influence on hair formation. In this case, the presence of an active locus in a few cells of the heterozygous female may be sufficient to maintain normal control, and hypotrichosis would occur only if all normal allele-bearing $\mathrm{X}$ chromosomes were inactive at the appropriate stage in development.

\section{Summary}

Partial anodontia and diminished activity of sweat glands were demonstrated in females heterozygous for anhidrotic ectodermal dysplasia. Results of thermally-induced sweating and histological examination of skin sections in carriers and controls indicated a quantitative deficiency of sweat glands in the carriers. Together with the patchy distribution of sweating these findings were consistent with the inactive $\mathrm{X}$ chromosome theory. There was no obvious gene effect on the hair of carrier females.

\section{REFERENCES}

Battersby, J. (1936). Ectodermal dysplasia with complete anodontia. Dent. Mag. (Lond.), 53, 427.

Bernard, R., Giraud, F., Rouby, M., and Hartung, M. (I963). A propos de sept observations de dysplasie ectodermique chez des sujets de sexe féminin dont six dans la même famille. Discussion génétique. Arch. franc. Pédiat., 20, I05I.

Brain, R. T. (1937). Familial ectodermal defect. Proc. roy. Soc. Med., 3I, 69.

Bruno, F. E., and Engelhardt, H. T. (1944). Hereditary ectodermal dysplasia. Ann. intern. Med., 20, I 40.

Clarke, R. E., and McCance, R. A. (1934). Familial sex-linked ectodermal dysplasia with incomplete forms. Arch. Dis. Childh., 9, 39.

Clouston, H. R. (1939). The major forms of hereditary ectodermal dysplasia (with an autopsy and biopsies on the anhydrotic type). Canad. med. Ass. F., 40, I.

Cockayne, E. A. (1933). Inherited Abnormalities of the Skin and its Appendages. Oxford University Press, London.

Darwin, C. (1875). The Variation of Animals and Plants under Domestication, 2nd ed., Vol. 2, p. 3 19. Murray, London.

De Silva, P. C. C. (I939). Hereditary ectodermal dysplasia of anhydrotic type. Quart. F. Med., 8, 97.

Everett, F. G., Jump, E. B., Sutherland, W. F., Savara, B. S., and Suher, T. (I952). Anhidrotic ectodermal dysplasia with anodontia: a study of 2 families. F. Amer. dent. Ass., 44, 173.

Felsher, Z. (r944). Hereditary ectodermal dysplasia: report of a case with experimental study. Arch. Derm. Syph. (Chic.), 49, 4 IO.
Glass, L. C., and Yost, D. H. (1939). Inherited inability to sweat. f. Hered., 30, 477.

Grahnen, H. (1962). Hereditary factors in relation to dental caries and congenitally missing teeth. In Genetics and Dental Health, ed. C. J. Witkop, p. 194. McGraw Hill, New York.

Grant, R., and Falls, H. F. (1944). Anodontia. Report of case associated with ectodermal dysplasia of anhidrotic type. Amer. F. Orthodont., 30, 661.

Guilford, S. H. (1883). A dental anomaly. Dent. Cosmos, 25, 113.

Guttmann, L. (1940). Topographic studies of disturbances of sweat secretion after complete lesions of peripheral nerves. $\mathcal{f}$. Neurol. Psychiat., 3, 197.

Halperin, S. L., and Curtis, G. M. (I942). Anhidrotic ectodermal dysplasia associated with mental deficiency. Amer. F. ment. Defic., 46, 459 .

Helweg-Larsen, H. F., and Ludvigsen, K. (1946). Congenital familial anhidrosis and neurolabyrinthitis. Acta derm.-venereol. (Stockh.), 26, 489.

Kline, A. H., Sidbury, J. B., Jr., and Richter, C. P. (1959). The occurrence of ectodermal dysplasia and corneal dysplasia in one family. F. Pediat., 55, 355 .

Kuno, Y. (1956). Human Perspiration. Thomas, Springfield, Illinois.

Levit, S. G. (1936). The problem of dominance in man. F. Genet., 33, 4 II.

Lipscomb, L. L., and Manonmani, H. (1952). Hereditary ectodermal dysplasia with report of 3 cases of the anhydrotic variety. f. Indian med. Ass., 21, 359.

Lipton, I., and Roberts, M. H. (1950). Hereditary ectodermal dysplasia of the anhidrotic type. Amer. F. Dis. Child., 79, 504.

Lord, L. W., and Wolfe, W. D. (1938). Hereditary ectodermal dysplasia of the anhidrotic type. Arch. Derm. Syph. (Chic.), 38, 893.

Lyon, M. F. (I96I). Gene action in the X-chromosome of the mouse (Mus musculus L.). Nature (Lond.), 190, 372.

Malagon, V., and Taveras, J. E. (1956). Congenital anhidrotic ectodermal and mesodermal dysplasia: report of 2 cases with atrichia and amastia. Arch. Derm., 74, 253.

Mallmann-Mühlberger, E., and Helwig, H. (1964). Familiäre ektodermale Dysplasie vom hidrotischen Typ. Ann. paediat. (Basel), 202, 358.

Metson, B. F., and Williams, B. K. (1952). Hereditary ectodermal dysplasia of the anhidrotic type: report of a case in a negro. f. Pediat., 40, 303.

Minor, V. (1927). Cited by Kuno (1956).

Mohler, D. N. (1959). Hereditary ectodermal dysplasia of the anhidrotic type associated with primary hypogonadism. Amer. F. Med., 27,682 .

Rademaker, G. A. (1933). Congenital (hereditary) dysplasia of the ectoderma. Acta paediat. (Uppsala), 15, 57.

Roberts, E. (1929). The inheritance of anhidrosis associated with anadontia. F. Amer. med. Ass., 93, 277.

Sackett, L. M., Marans, A. E., and Hursey, R. J. (1956). Congenital ectodermal dysplasia of the anhidrotic type. Oral Surg., 9, 659.

Seagle, J. B. (1954). Anhidrotic hereditary ectodermal dysplasia: report of 2 cases in a brother and sister. F. Pediat., 45, 688 .

Spira, L. (1947). Congenital ectodermal dysplasia. Acta med. scand., $127,570$.

Stadler, H., and Blackstone, C. H. (I942). Hereditary ectodermal dysplasia of the anhidrotic type. A report of 2 cases. F. Pediat., $21,229$.

Sunderman, F. W. (I94I). Persons lacking sweat glands: hereditary ectodermal dysplasia of the anhidrotic type. Arch. intern. Med., $67,846$.

Sutarman, and Thomson, M. L. (1952). A new technique for enumerating active sweat glands in man. F. Physiol. (Lond.), r17, 51 .

Tendlau, B. (I902). Ueber angeborene und erworbene Atrophia cutis idiopathica. Virchows Arch. path. Anat., 167, 465.

Thadani, K. I. (1934). The toothless man of Sind. F. Hered., 25, 483. Thannhauser, S. J. (1936). Hereditary ectodermal dysplasia of the "anhidrotic type" with symptoms of adrenal medulla insufficiency and with abnormalities of the bones of the skull. f. Amer. med. Ass., 106, 908 .

Thoma, K. H., and Allen, F. W. (1940). Anodontia with ectodermal dysplasia. Amer. F. Orthodont., 26, 503.

Thurnam, J. (1848). Two cases in which the skin, hair and teeth were very imperfectly developed. Med.-chir. Trans., 31, 7 I. 
Tritsch, H. (1963). Cytogenetische Untersuchungen bei verschiedenen dermatologischen und andrologischen Krantheitsbildern. Z. Haut-u. Geschl. Kr., 34, 329.

Upshaw, B. Y., and Montgomery, H. (1949). Hereditary anhidrotic ectodermal dysplasia: a clinical and pathologic study. Arch. Derm. Syph. (Chic.), 60, I 170.

Wagner, H. N., Jr. (1952). Electrical skin resistance studies in two persons with congenital absence of sweat glands. ibid., 65, 543. Weech, A. A. (1929). Hereditary ectodermal dysplasia (congenital ectodermal defect). Amer. F. Dis. Child., 37, 766. Wells, R. S., and Kerr, C. B. (1966). The histology of ichthyosis f. invest. Derm. In the press.

Werther, R., and Rothenberg, F. (1939). Anodontia. Amer. $\frac{\mathscr{c}}{8}$ Orthodont., 25, 6r.

White, A. G. (I964). Hereditary ectodermal dysplasia wơ megaloblastic anaemia. Brit. f. clin. Pract., 18, 541.

Zeligs, M. (1932). Hereditary ectodermal dysplasia, anhidrotic ty Amer. F. Dis. Child., 44, 394. 